\title{
Functional outcomes in children with reduction glossectomy for vascular malformations - "less is more!"
}

\author{
John K. Thomas' ${ }^{1}$, Vivek Samuel Gaikwad', Telugu Ramesh Babu², \\ John Mathai', Rohit Srinivas ${ }^{1}$, Immanuel Sampath Karl ${ }^{1}$ \\ Departments of ${ }^{l}$ Paediatric Surgery and ${ }^{2}$ Pathology, Christian Medical College, Vellore, India
}

\begin{abstract}
J Korean Assoc Oral Maxillofac Surg 2021;47:209-215)
Objectives: Vascular malformation (VM) of the tongue can cause true macroglossia in children. Reduction glossectomy provides primary relief when sclerotherapy has failed or is not possible. In this study, we evaluated the surgical role in functional outcome of reduction glossectomy performed for VM of the tongue.

Patients and Methods: We evaluated the functional and surgical outcomes of seven children who were treated at a tertiary care centre in Southern India between 2013 and 2018.

Results: Six children underwent median glossectomy, while one child underwent lateral glossectomy. Functional assessment was performed at least 2 years after the date of surgery. At the time of assessment, speech was comprehensible for three children and was occasionally unintelligible in four children. Taste and swallowing were normal in all seven children. Six children exhibited a minimal residual lesion after surgery, of which only one was symptomatic. Residual lesions were managed with sclerotherapy $(\mathrm{n}=3)$, observation $(\mathrm{n}=2)$, or repeat surgery $(\mathrm{n}=1)$.

Conclusion: Reduction glossectomy in children with macroglossia secondary to VMs has acceptable outcomes in terms of cosmesis and speech, with no gastronomic restriction.
\end{abstract}

Key words: Macroglossia, Glossectomy, Vascular malformation, Treatment outcome, Sclerotherapy

[paper submitted 2020. 9. 17 / revised 1st 2020. 11. 27, 2nd 2020. 12. 14, 3rd 2020. 12. 14 / accepted 2020. 12. 16]

\section{Introduction}

Macroglossia is defined as enlargement of the tongue that results in its protrusion beyond the teeth or alveolar ridge in its natural resting state ${ }^{1,2}$. Depending on the extent of involvement, macroglossia has been categorised as generalised or localised ${ }^{3}$. Based on aetiology, it is classified as either true or relative macroglossia. In true macroglossia, histological abnormalities are noted in the intrinsic tissue of the tongue that correlate with the findings of tongue enlargement. In relative macroglossia, the histology mostly is non-contributory,

\footnotetext{
John K. Thomas

Department of Paediatric Surgery, Christian Medical College, Ida Scudder Road, Vellore 632004, Tamilnadu, India

TEL: +91-416-2283369

E-mail:drjohntk@gmail.com

ORCID: https://orcid.org/0000-0001-7735-637X

(c) This is an open-access article distributed under the terms of the Creative Commons Attribution Non-Commercial License (http://creativecommons.org/ licenses/by-nc/4.0/), which permits unrestricted non-commercial use, distribution, and reproduction in any medium, provided the original work is properly cited. Copyright (C) 2021 The Korean Association of Oral and Maxillofacial Surgeons. All rights reserved.
}

and hypoplastic mandible and maxilla proffer a pathological explanation $^{4}$. In true macroglossia, when a large protuberant tongue instigates a mass effect, surgery is performed to improve quality of life by reducing the volume of the tongue while preserving function.

Assessment of the functional outcome includes anthropometric measurements of the tongue in paediatric patients undergoing glossectomy based on the normal somatic growth of the tongue. As the size of the tongue varies with age, it is rational to assess the outcome of surgery in terms of function rather than direct measurement of its size. The aim of our study was to evaluate surgical and functional outcomes of reduction glossectomy performed for vascular malformation (VM) of the tongue.

\section{Patients and Methods}

This is a single-institution, retrospective, descriptive study carried out at a tertiary care centre in India. We included all children with macroglossia due to VM who underwent re- 
duction glossectomy from January 2013 to December 2018 at Christian Medical College, Vellore. This study was performed with approval of Research Institutional Review Board of Christian Medical College, Vellore (IRB No. 13009). Details of the demographic profile, presentation, nutritional status, radiological characterisation, histopathology of the lesion, clinical course, preoperative/adjuvant interventions, all surgical procedures, and presence of residual or recurrent lesions were collated from the medical records. The pathology report and radiological images were reviewed to note the diagnosis and extent of involvement. Nutritional assessment was calculated using World Health Organization (WHO) growth standards. Underweight was considered at less than the 5 th percentile weight for age, and stunting was assigned if height was less than the 5th percentile for age according to WHO 2006 and Indian Academy of Paediatrics (IAP) 2015 combined height and weight charts ${ }^{5}$.

Outcomes were reviewed after a minimum postoperative interval of two years and entered in a proforma. Variables assessed were feeding habits, taste perception, sensation of the tongue, occlusion, cosmesis, parental satisfaction, and speech output. All variables except speech were assessed by tel-
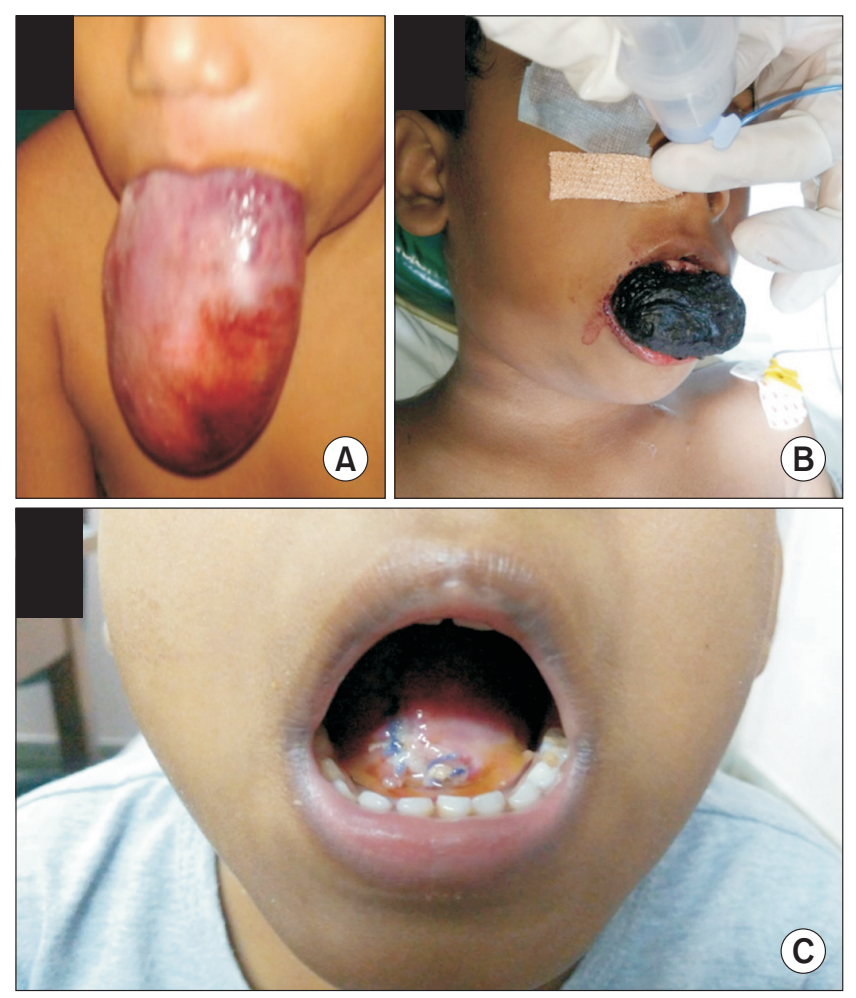

Fig. 1. A. Clinical picture of Patient 1. B, C. Clinical pictures of Patient 2. Preoperative (B) and three weeks after surgery (C).

John K. Thomas et al: Functional outcomes in children with reduction glossectomy for vascular malformations - "less is more!". J Korean Assoc Oral Maxillofac Surg 2021 ephonic interviews of one or both parents and the child after obtaining informed consent.

Speech was assessed by understandability. A recorded twominute audio/video sample of the child's extempore speech based on a prompt to describe a hobby or school/leisure activity was considered for the assessment. Speech understandability was defined as the degree to which the speaker's message was understood by the listener. The sample also served to assess the fluency of speech delivery. The recorded samples were assessed by three clinicians for perceptual judgement. One of the three assessors was an independent clinician who was not part of this study. The average score using the Henningsson et al. ${ }^{6}$ four-point speech understandability rating scale was employed for final speech assessment. This is a 4-category ordinal scale, with a minimum score of 0 when the speech was within normal limits and constantly easy to understand, while a maximum score of 3 denoted speech that

Table 1. Baseline parameters

\begin{tabular}{|c|c|}
\hline Parameter & Value \\
\hline \multicolumn{2}{|l|}{ Patient distribution } \\
\hline Male:female & $3: 4$ \\
\hline \multicolumn{2}{|l|}{ Age (yr) } \\
\hline Median age at presentation & $3(1.5-5)$ \\
\hline Median age at assessment & $8.6(3.5-11)$ \\
\hline \multicolumn{2}{|l|}{ Other features at presentation } \\
\hline Severely impaired speech & 7 \\
\hline Malocclusion & 7 \\
\hline Drooling & 7 \\
\hline Unable to ingest solids & 3 \\
\hline Unable to ingest semisolids & 2 \\
\hline Undernourished & 5 \\
\hline Underweight and stunted & 3 \\
\hline Underweight only & 1 \\
\hline Stunted only & 1 \\
\hline \multicolumn{2}{|l|}{ MRI - extent of the lesion } \\
\hline $\begin{array}{l}\text { Confined to the oral tongue and floor of } \\
\text { the mouth }\end{array}$ & 2 \\
\hline Lesion extending into the cervical region & 5 \\
\hline $\begin{array}{l}\text { Anterior triangle - submandibular and } \\
\text { submental triangles }\end{array}$ & 2 \\
\hline $\begin{array}{l}\text { Anterior triangle - extending into the } \\
\text { carotid and muscular triangle }\end{array}$ & 2 \\
\hline $\begin{array}{l}\text { Involving both the anterior and } \\
\text { posterior triangles with extension into } \\
\text { the superior mediastinum }\end{array}$ & 1 \\
\hline Bone involvement (mandible/maxilla) & 2 \\
\hline \multicolumn{2}{|l|}{ Pathology } \\
\hline Lymphovenous malformation & 4 \\
\hline Lymphatic malformation & 3 \\
\hline \multicolumn{2}{|l|}{ Surgery details } \\
\hline Median glossectomy & 6 \\
\hline Lateral glossectomy & 1 \\
\hline Debulking of the neck lesion & 2 \\
\hline Tracheostomy & 2 \\
\hline
\end{tabular}

(MRI: magnetic resonance imaging)

Values are presented as ratio, median (range), or number of patients. John K. Thomas et al: Functional outcomes in children with reduction glossectomy for vascular malformations - "less is more!”. J Korean Assoc Oral Maxillofac Surg 2021 
was severely impaired and difficult to understand most of the time. A score of 2 or 3 implied difficult to comprehend speech production.

Feeding habits and swallowing were judged with the functional oral intake scale described by Crary et al. ${ }^{7}$. This is a seven-point rating score, scored with a minimum of 1 and maximum of 7 . A score of 4 or greater indicates oral intake with decreased restriction.

\section{Results}

During the study period, we treated 43 children with VA of the head and neck region with varying degree of tongue involvement. Seven patients had macroglossia with pure or mixed lymphatic histology that required reduction glossectomy, and all were included in the study. Age at presentation ranged from 1.5 to 5 years (median, 3 years). Outcomes were assessed after 2 to 7.5 years (median interval, 5.16 years)

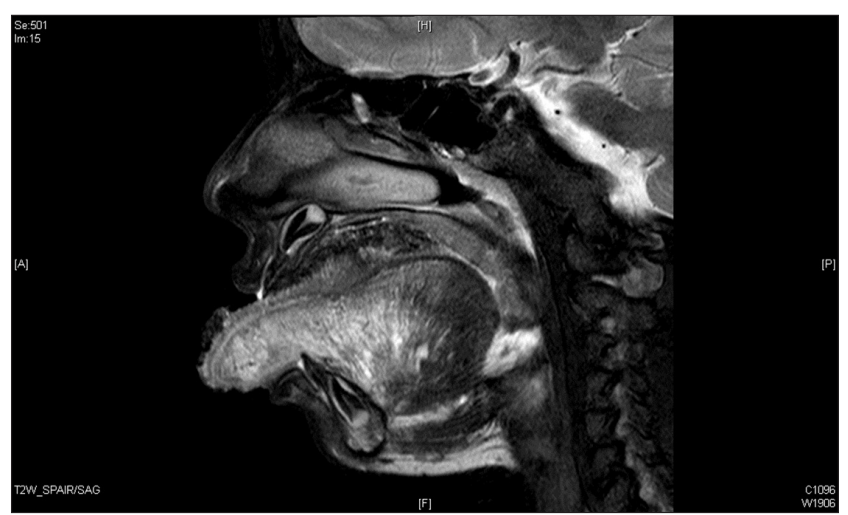

Fig. 2. Preoperative magnetic resonance imaging. John K. Thomas et al: Functional outcomes in children with reduction glossectomy for vascular malformations - “less is more!”. J Korean Assoc Oral Maxillofac Surg 2021 from the date of surgery, which corresponded to the age range of 3.5 to 11 years (median, 8.6 years).

Six of the seven children had the tongue lesion at birth, the other presented at 11 months of age. Progression of disease was gradual in five patients, while two patients exhibited a sudden increase in tongue size. At time of presentation, all patients had grossly enlarged and protruded tongue with inability to appose their lips.(Fig. 1. A, 1. B) None of the patients had stridor, sleep apnoea, or features of micro aspiration or nutritional anaemia. Despite the grossly enlarged tongue, all seven patients were able to ingest liquids orally. Other symptoms at presentation are depicted in Table 1.

Magnetic resonance imaging was performed for all patients to assess the extent of tongue involvement.(Table 1, Fig. 2) In one patient, the lesion was lateralised to the left side, five showed varying degrees of diffuse involvement of the tongue, and one lesion predominantly involved in the anterior two-thirds of the tongue. All lesions were slow flow lesions and were either lymphatic, venous, or mixed veno-lymphatic. One patient exhibited intrathoracic extension.

Reduction glossectomy was performed in all patients. Five of these children underwent preoperative sclerotherapy either with sodium tetradecyl sulphate foam or bleomycin foam, and three patients exhibited some form of a response. One patient underwent marsupialization of the tongue lesion before visiting our institute with no effect. The indication for reduction glossectomy was primarily size of the tongue or intervening complications like bleeding, necrosis, or recurrence. The surgical procedures performed were Köle inverted V glossectomy $(n=6)$ and unilateral hemi glossectomy $(n=1)$.

Two patients with extensive neck involvement exhibited a compromised pharyngeal space and airway after sclerotherapy. Both patients had to undergo debulking of the neck lesion
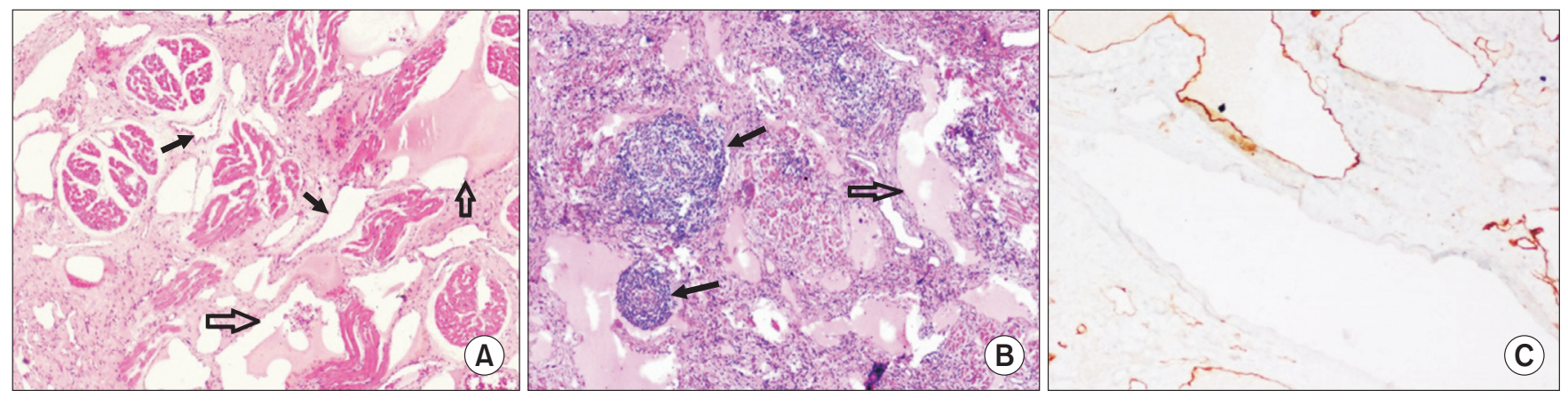

Fig. 3. A. Vascular lesion penetrating between skeletal muscle fibres displaying ecstatic venous (narrow arrows) and lymphatic channels (broad arrows) (H\&E staining, $\times 100$ ). B. Lymphangioma showing dilated lymphatic channels containing serous fluid (broad arrow) and stroma with lymphoid aggregates (narrow arrows) (H\&E staining, $\times 100$ ). C. D2-40 antibody showing positive immunoreaction for lymphatic endothelium and negative reaction for venous endothelium (IHC staining, $\times 100)$.

John K. Thomas et al: Functional outcomes in children with reduction glossectomy for vascular malformations - “less is more!”. J Korean Assoc Oral Maxillofac Surg 2021 
with tracheostomy. One child required an adjuvant short-term feeding gastrostomy.

There were no surgical complications from glossectomy per se, but there was bleeding from the tracheostomy in the two such treated children.

Pathological examination revealed lympho-venous malformation $(n=4)$ and lymphatic malformation $(n=3)$. These vascular lesions involved the subepithelial region, penetrating between the skeletal muscle fibres and extending into the deep underlying adipose tissue.(Fig. 3)

Six patients had residual disease in the tongue, floor of the mouth, or neck. All tongue lesions were small except one that became prominent episodically with every upper respiratory infection. The residual lesions were managed with revision glossectomy in one child, observation in two children, and adjuvant sclerotherapy $(n=3)$ in three children. Only two patients responded completely to adjuvant therapy, while the others remain asymptomatic with small residual lesion.

Assessment of the outcomes of surgery showed that all patients could accommodate their tongues within their dental arches at rest. Speech was assessed in all seven patients and was comprehensible in all of them, with a score of $0(n=3)$ or $1(n=4)$. All patients exhibited good initiation of conversation without any social restriction or frustration about their articulation.

All children exhibited some degree of residual malocclusion, but only one child had difficulty biting with their incisors due to reverse overjet. All children reported thermal sensations and were able to distinguish between saltiness, sweetness, and bitter tastes. After surgery, all patients exhibited improvements in feed tolerance to a score of 7. On nutritional follow-up, all children had significant improvement

Table 2. Outcome measurements

\begin{tabular}{lc}
\multicolumn{1}{c}{ Outcome } & $\begin{array}{c}\text { No. of } \\
\text { patients }\end{array}$ \\
\hline Residual lesion & 6 \\
Symptomatic & 1 \\
Asymptomatic & 5 \\
Speech (understandability - Henningsson et al. ${ }^{6}$ ) & 3 \\
Within normal limits and consistently easy to & \\
$\quad$ understand (score 0) & 4 \\
Sometimes difficult to understand (score 1) & 0 \\
$\quad$ Often difficult to understand (score 2) & 7 \\
Difficult to understand most of the time (score 3) & \\
Swallowing (functional oral intake scale - Crary et al. ${ }^{7}$ ) & \\
$\quad$ No food intake restrictions (score 7) & 7 \\
Gustatory and thermal sensation of the tongue & \\
$\quad$ Preserved & \\
\hline John K. Thomas et al: Functional outcomes in children with reduction glossectomy for \\
vascular malformations - "less is more!". J Korean Assoc Oral Maxillofac Surg 2021
\end{tabular}

in nutritional status in terms of improvement in percentile, in accordance with the chart. All also showed significant improvement in nutritional status in terms of height and weight. (Tables 2, 3) The parental and patient satisfaction with the surgical outcome was universal in our cohort.

\section{Discussion}

Vascular anomaly (VA) is classified as vascular tumour or $\mathrm{VM}^{8}$. Pure lymphatic malformation or combined lymphovenous malformation is the most common cause of macroglossia in children and is apparent at birth in $60 \%$ of all such patients, with $95 \%$ becoming symptomatic after 2 years ${ }^{2}$. Our cohort showed similar findings. Management of VA depends on type of lesion, area of involvement, type of presentation, and associated symptoms ${ }^{9-11}$. Sirolimus is a novel adjuvant therapy for VM with promising reduction ${ }^{12-15}$. It is not available for over the counter use for this condition despite being efficacious because of major blood dyscrasias and gastrointestinal toxicities in a significant proportion of users ${ }^{12}$. Patients must be monitored for recurrence or long-term toxicities, and sirolimus use should be sanctioned by a constituted medical board. This cohort was not exposed to sirolimus as the patients had advanced disease at presentation.

Reduction glossectomy procedures are subdivided into two groups: glossectomy along the median line and peripheral glossectomy ${ }^{9}$. Care in preserving the lingual arteries and hypoglossal nerve ensures maintenance of the viability and function of the tongue. Since the neurovascular bundle lies ventrally on either side of the tongue, a median approach greatly reduces the chance of injury.

The most widely practiced reductive procedures for true macroglossia are keyhole techniques described by Morgan et al. $^{16}$ and resection and approximation of the tongue by Köle ${ }^{17-21}$. The keyhole technique is preferred to reduce the central bulk of the tongue. In our study group, six patients with diffuse involvement of the tongue underwent the Köle procedure, while one child with localised lesion underwent hemi glos-

Table 3. Nutritional outcomes

\begin{tabular}{lcc}
\hline & $\begin{array}{c}\text { Weight greater than } \\
\text { 50th percentile }\end{array}$ & $\begin{array}{c}\text { Height greater than } \\
\text { 50th percentile }\end{array}$ \\
\hline Preoperative & 1 & 0 \\
Postoperative & 5 & 3 \\
$(1.5$ yr after surgery $)$ & & \\
\hline
\end{tabular}

Values are presented as number of patients.

John K. Thomas et al: Functional outcomes in children with reduction glossectomy for vascular malformations - "less is more!”. J Korean Assoc Oral Maxillofac Surg 2021 
sectomy. All patients had acceptable outcomes with good cosmesis, satisfactory speech understandability, decent taste perception, and normal swallowing. Therefore, Köle's procedure is appropriate for diffuse involvement as it is technically easy to perform in a tongue of massive proportion.

Speech is the efficient primary mode of human communication and is essential for emotional well-being. Speech outcomes after glossectomy have been extensively studied in the adult population using the Speech Handicap Index (SHI). Adult studies demonstrated that SHI will improve with time and return to its baseline preoperative score after approximately 1 year of surgery, but with persistent clinical impairment ${ }^{22}$. Paediatric SHI validated for Indian languages are unavailable. Therefore, we used the speech understandability scoring developed by Henningsson et al. ${ }^{6}$. In all patients, speech quality improved to a score of $0(n=3)$ or $1(n=4)$ after surgery. Four of the six children who underwent Köle's procedure exhibited a score of 1 , but all the other children including the patient who underwent hemi glossectomy had normal speech with a score of 0 . Abnormalities observed in three children with a score of 1 were occasional omission and distortion. Good initiation of speech without any frustration about the quality of articulation or social restriction implies that there is no detectable emotional distress due to articulation.

The mechanical role of the tongue is essential for bolus transfer in mastication and oropharyngeal transfer of the bolus while initiating deglutition. After surgery, all patients achieved near normal chewing and swallowing, which was evident by improvement of their functional oral intake score and nutritional status. It has been demonstrated in adults, following partial or total glossectomy, that most patients develop more than one compensatory mechanism to overcome swallowing-related impairments and complications ${ }^{23}$. In all patients, we observed nutritional recovery with improvement in growth percentile.(Tables 2, 3)

The localisation of taste to distinct areas of the tongue became obsolete with these patients, and taste was appreciated on the palate, epiglottis, and proximal oesophagus. Taste buds are concentrated around the circumvallate papillae, and a moderate number of them are found on the anterior and lateral surfaces of the tongue ${ }^{24,25}$. In Köle's procedure, there is loss of tissue from the anterior aspect and tip of the tongue. In all patients, we aimed to reduce loss of tissue near the circumvallate papillae. This would preserve more taste buds and conserve greater taste sensation.

Reduction glossectomy was carried out to reduce tongue bulk with preservation of adequate tissue. After glossectomy, six patients had minimal residual lesions on the tongue. With adjuvant therapies, all except one patient continued to be asymptomatic without an increase in size of the lesions. The symptomatic child underwent revision surgery. Aggressive excision of the tissue might impair function. As most residual lesions are asymptomatic, it is worthwhile to compromise the completeness of resection to leave adequate tongue tissue for a better functional outcome. Residual lymphatic malformations, which are exacerbated with upper respiratory tract infections, can be managed with antibiotics ${ }^{19}$. Larger lesions on the tongue and neck can be addressed with sclerotherapy with or without re-excision or debulking.

Speech was assessed by three assessors, of which two were part of the treating team. This could have created an observational bias. However, the scores given independently by all three assessors were comparable. Other limitations of the study were the small sample size, wide range in age of children, and retrospective nature of the study. Despite these limitations, the study remains relevant, as glossectomy in the paediatric age group is a rare surgical procedure, and adequate literature is not available for functional outcome after glossectomy in children with VM.

This series demonstrates that functional outcomes of speech, gustatory appreciation, oral appreciation of thermal sensory input, and deglutition are largely preserved with proper surgical technique. This is congruent with other studies where reduction glossectomy was performed for macroglossia due to other non-malignant pathologies ${ }^{18,26,27}$.

\section{Conclusion}

Reduction glossectomy can be considered a reliable option to control macroglossia caused by lymphatic and venolymphatic malformations after failed non-surgical therapy. Symptomatic residual lesions on the tongue following glossectomy can be managed conservatively in most instances.

\section{ORCID}

John K. Thomas, https://orcid.org/0000-0001-7735-637X

Vivek Samuel Gaikwad, https://orcid.org/0000-0002-91593440

Telugu Ramesh Babu, https://orcid.org/0000-0002-00785704

John Mathai, https://orcid.org/0000-0003-1910-2499

Rohit Srinivas, https://orcid.org/0000-0002-6774-1765 
Immanuel Sampath Karl, https://orcid.org/0000-00033114-9687

\section{Authors' Contributions}

J.K.T. participated in the study design, data management, manuscript writing and administration. V.S.G. and T.R.B. participated in the data collection and manuscript preparation. J.M. participated in the preparation and review of manuscript, guide and critical revision. R.S. participated in the original concept and manuscript review. I.S.K. participated in the review of manuscript, guide and critical revision. All authors read and approved the final manuscript.

\section{Ethics Approval and Consent to Participate}

This study was performed with approval of Research Institutional Review Board of Christian Medical College (IRB No. 13009).

\section{Consent for Publishing Photographs}

Written informed consent was obtained from the patients for publication of this article and accompanying images.

\section{Conflict of Interest}

No potential conflict of interest relevant to this article was reported.

\section{References}

1. Balaji SM. Reduction glossectomy for large tongues. Ann Maxillofac Surg 2013;3:167-72. https://doi.org/10.4103/2231-0746.119230

2. Walker WA, Goulet O, Kleinman RE, Sherman PM, Schneider BL, Sanderson IR. Pediatric gastrointestinal disease: pathophysiology, diagnosis, management. 4th ed. Hamilton: BC Decker; 2004:1158.

3. Myer CM 3rd, Hotaling AJ, Reilly JS. The diagnosis and treatment of macroglossia in children. Ear Nose Throat J 1986;65:444-8.

4. Vogel JE, Mulliken JB, Kaban LB. Macroglossia: a review of the condition and a new classification. Plast Reconstr Surg 1986;78:715-23.

5. Khadilkar V, Khadilkar AV, Kajale N. Indian growth references from 0-18-year-old children and adolescents - a comparison of two methods. Indian J Endocrinol Metab 2019;23:635-44. https://doi. org/10.4103/ijem.IJEM_555_19

6. Henningsson G, Kuehn DP, Sell D, Sweeney T, Trost-Cardamone JE, Whitehill TL; Speech Parameters Group. Universal parameters for reporting speech outcomes in individuals with cleft palate. Cleft Palate Craniofac J 2008;45:1-17. https://doi.org/10.1597/06-086.1

7. Crary MA, Mann GD, Groher ME. Initial psychometric assessment of a functional oral intake scale for dysphagia in stroke patients.
Arch Phys Med Rehabil 2005;86:1516-20. https://doi.org/10.1016/ j.apmr.2004.11.049

8. Bell DJ, Gaillard F. ISSVA classification of vascular anomalies [Internet]. Kew: Radiopaedia [cited 2020 Sep 7]. Available from: https://radiopaedia.org/articles/issva-classification-of-vascularanomalies

9. Vlachou E, Dalal M, Monaghan A, Nishikawa H. Acute exacerbation of macroglossia. Br J Plast Surg 2005;58:877-80. https://doi. org/10.1016/j.bjps.2004.12.010

10. Wiegand S, Eivazi B, Zimmermann AP, Neff A, Barth PJ, Sesterhenn AM, et al. Microcystic lymphatic malformations of the tongue: diagnosis, classification, and treatment. Arch Otolaryngol Head Neck Surg 2009;135:976-83. https://doi.org/10.1001/archoto. 2009.131

11. Lahiri A, Kok K, Sharp I, Nishikawa H. Acute exacerbation of macroglossia leading to necrosis of the anterior third of the tongue. J Plast Reconstr Aesthet Surg 2006;59:871-3. https://doi. org/10.1016/j.bjps.2005.12.005

12. Adams DM, Trenor CC 3rd, Hammill AM, Vinks AA, Patel MN, Chaudry G, et al. Efficacy and safety of sirolimus in the treatment of complicated vascular anomalies. Pediatrics 2016;137:e20153257.

13. Curry S, Logeman A, Jones D. Sirolimus: a successful medical treatment for head and neck lymphatic malformations. Case Rep Otolaryngol 2019;2019:2076798. https://doi.org/10.1155/2019/2076798

14. Hammer J, Seront E, Duez S, Dupont S, Van Damme A, Schmitz $\mathrm{S}$, et al. Sirolimus is efficacious in treatment for extensive and/or complex slow-flow vascular malformations: a monocentric prospective phase II study. Orphanet J Rare Dis 2018;13:191. https:// doi.org/10.1186/s13023-018-0934-Z

15. Lee BB. Sirolimus in the treatment of vascular anomalies. J Vasc Surg 2020;71:328. https://doi.org/10.1016/j.jvs.2019.08.246

16. Morgan WE, Friedman EM, Duncan NO, Sulek M. Surgical management of macroglossia in children. Arch Otolaryngol Head Neck Surg 1996;122:326-9.

17. Myers EN. Operative otolaryngology: head and neck surgery. 2nd ed. Philadelphia (PA): Elsevier; 2008:161-7.

18. Davalbhakta A, Lamberty BG. Technique for uniform reduction of macroglossia. Br J Plast Surg 2000;53:294-7. https://doi. org/10.1054/bjps.1999.3311

19. Melville JC, Menegotto KD, Woernley TC, Maida BD, Alava I 3rd. Unusual case of a massive macroglossia secondary to myxedema: a case report and literature review. J Oral Maxillofac Surg 2018;76:119-27. https://doi.org/10.1016/j.joms.2017.06.033

20. Chung IH, Song SI, Kim ES. Central tongue reduction for macroglossia. J Korean Assoc Oral Maxillofac Surg 2003;29:191-4.

21. Köle H. Results, experience, and problems in the operative treatment of anomalies with reverse overbite (mandibular protrusion). Oral Surg Oral Med Oral Pathol 1965;19:427-50. https://doi. org/10.1016/0030-4220(65)90002-2

22. Dzioba A, Aalto D, Papadopoulos-Nydam G, Seikaly H, Rieger J, Wolfaardt J, et al.; Head and Neck Research Network. Functional and quality of life outcomes after partial glossectomy: a multi-institutional longitudinal study of the head and neck research network. J Otolaryngol Head Neck Surg 2017;46:56. https://doi.org/10.1186/ s40463-017-0234-y

23. Halczy-Kowalik L, Wiktor A, Rzewuska A, Kowalczyk R, Wysocki $\mathrm{R}$, Posio V. Compensatory mechanisms in patients after a partial or total glossectomy due to oral cancer. Dysphagia 2015;30:738-50. https://doi.org/10.1007/s00455-015-9652-z

24. Hall JE. Pocket companion to Guyton and Hall textbook of medical physiology. 12th ed. Philadelphia (PA): Saunders/Elsevier; 2012:1091.

25. Barrett KE, Barman SM, Boitano S, Brooks H. Ganong's review of medical physiology. 24th ed. New York: McGraw-Hill; 2012:764.

26. Elhalaby EE, Hassan HS, Almetaher HA. Reduction glossectomy for macroglossia in children. Ann Pediatr Surg 2015;11:115-9. 
https://doi.org/10.1097/01.XPS.0000462929.45595.1a

27. Bjuggren G, Jensen R, Strömbeck JO. Macroglossia and its surgical treatment. Indications and postoperative experiences from the orthodontic, phoniatric, and surgical points of view. Scand J Plast Reconstr Surg 1968;2:116-24. https://doi. org/10.3109/02844316809010493
How to cite this article: Thomas JK, Gaikwad VS, Babu TR, Mathai J, Srinivas R, Karl IS. Functional outcomes in children with reduction glossectomy for vascular malformations - "less is more!". J Korean Assoc Oral Maxillofac Surg 2021;47:209-215. https://doi.org/10.5125/jkaoms.2021.47.3.209 